\title{
Bacillus anthracis como ameaça terrorista
}

\author{
Bacillus anthracis as terrorist threat
}

Telma Abdalla de Oliveira Cardoso', Duarte Nuno Vieira²

RESUMO Após 2001, a utilização de patógenos reforçou seu emprego como arma de guerra. Este estudo descritivo tem por objetivo discutir estratégias de contingenciamento em ataque por anthrax, auxiliando no reconhecimento precoce e estabelecimento de medidas de contenção. Profissionais de saúde necessitam reconhecer a infecção, pois em atentados, o elemento-chave é médico e não militar. $\mathrm{O}$ anthrax por inalação é a forma de atentado mais provável com $100 \%$ de mortalidade, caso não haja tratamento imediato. É altamente resistente; tem período de incubação de um a seis dias; seus sintomas iniciais são similares à influenza; só permite diagnóstico em NB3; a vacina é aquela recomendada para ocupações de risco, de disponibilidade restrita; e requer profilaxia antibiótica longa.

PALAVRAS-CHAVES Bacillus anthracis; Bioterrorismo; Exposição a agentes biológicos; Risco; Saúde pública.

\begin{abstract}
As from 2001, the use of biological agents reinforced the possibility of its consolidation as warfare. This descriptive study aims to discuss the contingency strategies for anthrax attack, seeking early recognition and establishment of containment measures. Health professionals need to recognize the infection since the key-element during an attack is medical rather than military one. Anthrax inhalation is the most likely form of attack with $100 \%$ mortality rate, if no immediate treatment is provided. The virus is highly resistant; has an incubation period of one to six days; its early symptoms are similar to influenza's; diagnosis is only allowed in NB3; the vaccine is the one recommended for risk occupations, of restricted availability; and requires long antibiotic prophylaxis.
\end{abstract}

KEYWORDS Bacillus anthracis; Bioterrorism; Exposure to biological agents; Risk; Public health.

1 Fundação Oswaldo Cruz (Fiocruz), Escola Nacional de Saúde Pública Sergio Arouca (Ensp) - Rio de Janeiro (RJ), Brasil. abdalla@fiocruz.br

2 Universidade de Coimbra, Faculdade de Medicina, Instituto Nacional de Medicina Legal e Ciências ForensesCoimbra, Portugal. dnvieira@inml.mj.pt 


\section{Introdução}

O uso de substâncias químicas e de agentes biológicos como estratégia militar de dominação não constitui um artifício bélico recente. Situações de conflito envolvendo o emprego desse tipo de agente verificaram-se desde a antiguidade, tendo, todavia, adquirido maior visibilidade no decurso dos conflitos bélicos ocorridos no século XX. Os atentados terroristas de 11/09/2001, em Nova Iorque, seguidos da disseminação de esporos de Bacillus anthracis, vieram reforçar a possibilidade da consolidação do bioterrorismo como estratégia de correlação de forças no enfrentamento de interesses globais e incluíram o vocábulo na linguagem cotidiana de diversos países, incluindo o Brasil. Tais atentados motivaram a modificação da estrutura de defesa em diversos países e o aumento do aporte financeiro para o desenvolvimento e produção de novos medicamentos e vacinas.

A definição de bioterrorismo pode auxiliar no entendimento desse fenômeno. Segundo o Centers for Disease Control and Prevention, bioterrorismo é a disseminação deliberada de agentes biológicos, como bactérias e vírus, utilizados com o propósito de causar doença ou morte em populações, animais ou plantas (CDC, 2015). Esses agentes são normalmente encontrados na natureza, mas também podem ser oriundos de modificações genéticas, por meio da tecnologia do DNA recombinante, alterando características como: virulência, patogenicidade, resistência a drogas e forma de transmissão.

Alguns autores, como Radosavljević e Jakovljević (2007) e Morse (2003) ressaltam que o elemento principal presente nos atos de bioterrorismo é a surpresa. Sua descoberta pode levar horas ou dias e utiliza-se da dimensão psicológica como uma ferramenta importante para causar medo, pânico, ansiedade e insegurança na população, desestabilizando-a e gerando desconfiança nas autoridades governamentais, doenças, morte e prejuízos econômicos.
Diversos agentes biológicos foram estudados com o objetivo de verificar seu potencial de uso como agentes no âmbito de guerra biológica, porém poucos evidenciaram características satisfatórias para tal fim. E mesmo esses, para poderem ser usados como armas, necessitam ser submetidos a processos complexos que garantam a satisfação de requisitos múltiplos, nomeadamente a sua estabilidade à degradação pela manipulação e armazenamento durante os processos de transferência de energia implícitos na maioria dos cenários de disseminação, e, ainda, que o agente, uma vez liberado, se mantenha em doses infectantes numa área previsível. Estas condições demonstram a substancial dificuldade e até mesmo a inviabilidade da utilização desse tipo de armamento.

Ainda que os ataques bioterroristas sejam improváveis e possuam, até hoje, taxas de morbimortalidade baixas, o potencial de uma arma biológica permanece elevado. Nas últimas décadas, o avanço biotecnológico vem permitindo o progresso da genética com o desvendamento do genoma, motivando a discussão de seu uso para o campo político estratégico, no âmbito de potencial nova geração de armas biológicas (SUK ET AL., 2011). A síntese química dos poliovírus (CELLO; PAUL; WIMMER, 2002) e do bacteriófago $\varphi$ X174 (SMITH ET AL., 2003) são técnicas que devem ser vistas com cuidado pela possibilidade de seu uso dual.

Em face do exposto, afigura-se óbvio que tanto os sistemas nacionais de saúde pública como os profissionais de saúde devem estar preparados para lidar com os mais diversos tipos de agentes biológicos, incluindo os exóticos a seus países.

Os esporos do anthrax têm sido considerados uma das melhores opções em termos de arma para a guerra biológica já que podem ser produzidos facilmente, disseminados por aerossóis, produzirem altas taxas de mortalidade e serem armazenados a seco, permanecendo de forma viável durante décadas (CLIFFORD; FAUCI, 2011; CDC, 2010). 
O CDC divide os agentes biológicos em três categorias (A, B e C), conforme critérios que determinam sua potencialidade para serem utilizados como arma biológica. Dentre esses critérios estão a virulência, patogenicidade, dose infectante, modo de transmissão, morbidade, letalidade, período de incubação, estabilidade e potencial em se tornar endêmico (CDC, 2010). Por tal classificação, o B. anthracis pertence à categoria $\mathrm{A}$, onde estão os agentes com alto risco, por afetar negativamente a saúde pública, com altas taxas de letalidade, serem facilmente disseminados, necessitarem de ações especiais de prontidão dos serviços de saúde e alto risco à segurança nacional (CDC, 2010). Uma comparação entre o número de mortos ocasionados por uma bomba atômica de $\mathbf{1 2 . 5}$ Kt e pela liberação intencional de esporos de anthrax demonstra a potencialidade desse agente como arma. A bomba pode ocasionar cerca de 80.000 mortes, enquanto $100 \mathrm{~g}$. de esporos de anthrax podem acarretar de um a três milhões de mortes (ARORA ET AL., 2010).

Situações envolvendo cadáveres contaminados causam compreensível temor na população, requerendo o desenvolvimento de esforços que garantam adequada e segura concretização das diversas e necessárias fases de coleta, transporte, armazenamento e disposição final dos corpos. Essas tarefas são habitualmente executadas por militares, profissionais de atendimento emergencial e de sobrevivência, mas também podem ser feitas por outros intervenientes, nomeadamente voluntários, detentores de escassa ou nenhuma formação ou experiência, sobretudo no que se refere à manipulação de corpos nesses contextos de risco em particular.

O Brasil é um país emergente, inserido no processo de globalização, considerado um dos dez pontos turísticos mais visitados do mundo e nos últimos anos tem sediado eventos internacionais, recebendo um grande quantitativo de pessoas de todas as partes do mundo, atraindo representações diplomáticas e empresariais internacionais. Apesar de nunca ter sofrido um atentado bioterrorista, pode se tornar alvo.

A epidemiologia é uma disciplina básica da saúde pública voltada para a "[...] compreensão do processo saúde-doença no âmbito de populações [...]” e está “[...] fundamentada no raciocínio causal e no desenvolvimento de estratégias para as ações voltadas para a proteção e promoção da saúde da comunidade." (WALDMAN; ROSA, 1998, P. 1).

Porém, há pouco debate acerca de epidemias causadas acidentalmente ou pela liberação deliberada de agentes biológicos. Assim, uma inquietude a respeito do preparo dos profissionais de saúde e do sistema de saúde pública brasileiro para um evento de bioterrorismo por anthrax direcionou este estudo.

Nesse sentido, este artigo tem como objetivo discutir as estratégias de contingenciamento frente aos riscos provenientes de um ataque de bioterrorismo utilizando B. anthracis com o propósito de auxiliar os profissionais de saúde no reconhecimento precoce do ato de bioterrorismo e no estabelecimento de medidas adequadas de contenção e de proteção. Para tanto, fez-se um estudo de revisão bibliográfica, conduzido de acordo com os preceitos metodológicos de um estudo descritivo, cujo objetivo é a leitura, seleção e registro de tópicos de interesse para a pesquisa.

\section{Bacillus anthracis}

Anthrax é uma doença causada pelo Bacillus anthracis, gram positivos, aeróbicos e esporogênicos. Os esporos medem de 1 a $1,5 \times \mathrm{m}$ de largura por 3 a $10 \times \mathrm{m}$ de comprimento e são resistentes à desidratação, calor, radiação ultravioleta, bem como a alguns desinfetantes utilizados nos serviços de saúde (CLIFFORD; FAUCI, 2011; DUTTA; SUJATHA; SAHOO, 2010; CDC, 2010). Apresentam-se, no quadro 1, as principais características desse agente. 


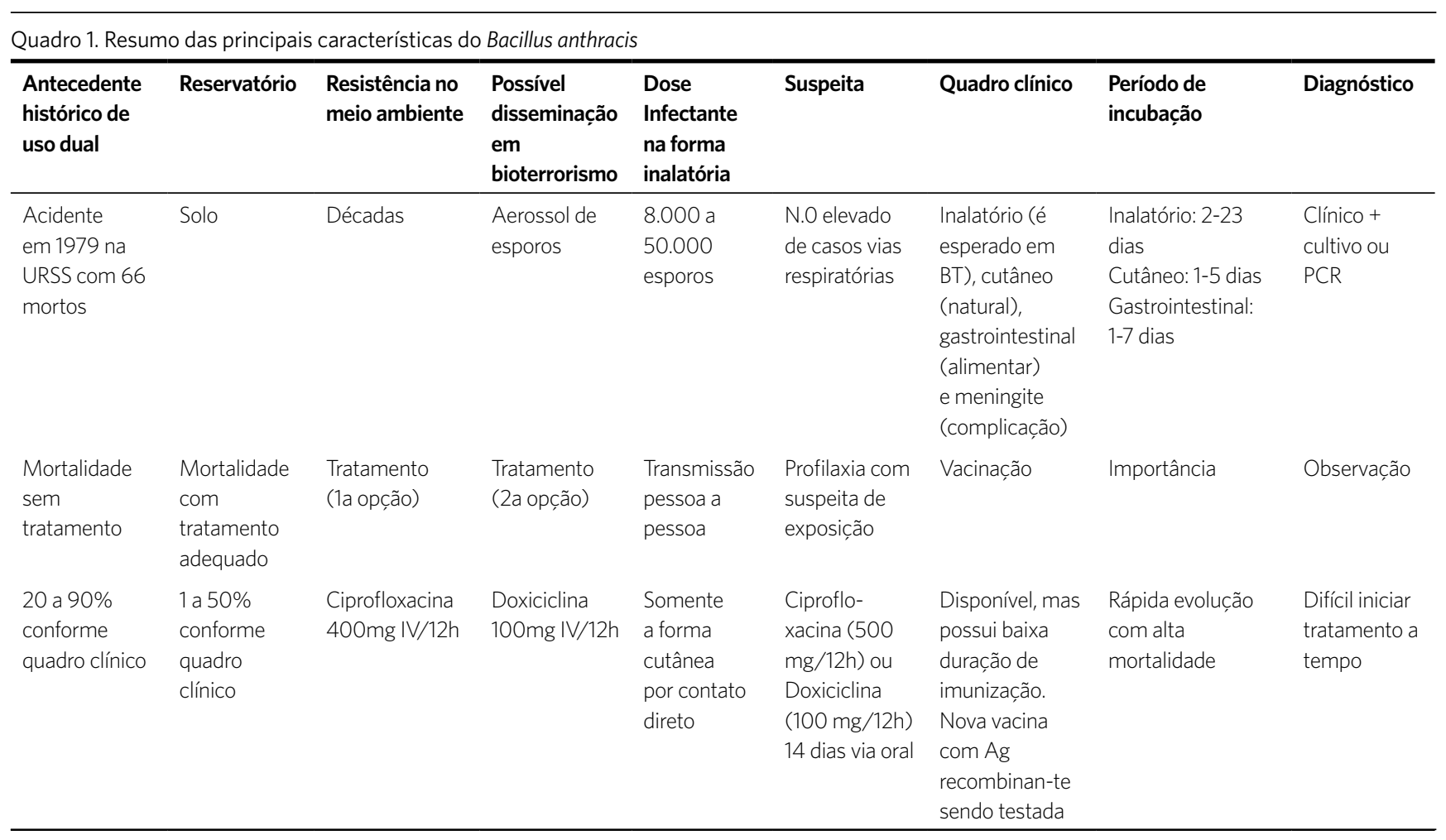

Fonte: CLIFFORD; DUTTA; SUJATHA; SAHOO, 2011; CDC, 2010; BOSSI et al., 2004; CDC, 2001.

A doença desenvolve-se de forma natural nos animais selvagens ou em herbívoros domésticos, bem como nos homens, após contato com animais infectados, produtos animais contaminados ou contato direto com o agente. A pele dos animais e o couro podem também conter esporos durante anos. Os seres humanos e os animais carnívoros são hospedeiros acidentais. É uma zoonose cosmopolita, endêmica em áreas agrícolas entre herbívoros (MARTIN; FRIEDLANDER, 2010).

Os esporos de B. anthracis podem permanecer viáveis no solo por muitos anos, e alguns fatores, tais como tempestades ou primavera chuvosa com verão seco, inundações e terremotos; além da ação humana manipulando a terra no preparo do solo para ser utilizado como pasto; ou para a construção de obras civis, como rodovias, hidroelétricas, açudes ou fundações de edificações podem reativar o foco de antraz no solo e têm sido associados ao aparecimento de epizootias (MARTIN; FRIEDLANDER, 2010).

B. anthracis tem três principais fatores de virulência: uma cápsula antifagocítica e duas exotoxinas, denominadas toxina letal e toxina do edema. Estas toxinas são responsáveis pelas principais manifestações clínicas: hemorragia, edema, necrose e morte (LIU; MOAYERI; LEPPLA, 2014; CDC, 2010).

Identificam-se três quadros clínicos de anthrax (SWEENEY ET AL., 2011; DUTTA; SUJATHA; SAHOO, 2011; BOSSI ET AL., 2004):

Cutâneo: representa 95\% dos casos naturais. É resultante da introdução do esporo através de uma lesão na pele. O surgimento de coceira na área afetada ocorre em algumas horas. Após um período de incubação de um a cinco dias, surgem as pápulas, indolores, progredindo para vesículas de um a três $\mathrm{cm}$ e posteriormente 
para úlceras. O pus só estará presente se houver contaminação secundária por bactérias piogênicas, como o Staphylococcus aureus. Após dois a seis dias, surge uma típica crosta negra com edema ao redor. Essa crosta cai após uma a três semanas, com uma taxa de cura de cerca de $80 \%$. Em $20 \%$ dos casos, pode haver febre, dor de cabeça e linfadenopatia, constituindo-se sinal de infecção sistêmica. A taxa de mortalidade na ausência de tratamento é de cerca de $20 \%$, sendo, todavia, inferior a $1 \%$ com tratamento (DOGANAY; METAN; ALP, 2010).

Gastrointestinal: esta forma é rara, acomete menos de $1 \%$ de todos os casos. Ocorre após ingestão do esporo decorrente do consumo de carne mal cozida ou crua de um animal infectado. Possui um período de incubação de um a sete dias. A escara característica ocorre mais frequentemente na parede do íleo terminal ou no ceco, embora a orofaringe, o estômago, o duodeno e o íleo superior possam ser afetados. O diagnóstico precoce é difícil, devido à sintomatologia inespecífica. A taxa de mortalidade é de aproximadamente 50\% (KLEMPNER ET AL., 2010). Há duas formas clínicas do anthrax gastrointestinal: intestinal e oro-esofágico. No anthrax intestinal, os esporos causam lesões ulcerativas em qualquer lugar, do jejuno ao ceco. Os pacientes frequentemente apresentam sintomas gastrointestinais inespecíficos, tais como náuseas, vômitos, anorexia, dor abdominal intensa e diarreia. Evolui em dois a cinco dias após o início dos sintomas para febre, ascite, hematêmese, aumento da circunferência abdominal, diarreia sanguinolenta aguda, choque, septicemia e morte. Os sintomas resultam de necrose grave e generalizada da escara inicial, juntamente com edema extremo de intestinos e do mesentério. Esse tipo de anthrax é muito difícil de ser diagnosticado. A taxa de mortalidade é de 20 a $60 \%$ (BEATTY ET AL., 2003). As manifestações clínicas do anthrax oro-esofágico incluem dor de garganta intensa, disfagia, febre, linfadenopatia cervical e edema. Úlceras podem estar presentes na boca e na garganta. Possui um período de incubação de 42 horas. A taxa de mortalidade varia entre 25 e $60 \%$. Com diagnóstico precoce, os pacientes podem ser curados, mas, como a sintomatologia é inespecífica, há dificuldade no diagnóstico, levando à alta taxa de mortalidade (SIRISANTHANA; BROWN, 2002).

Pulmonar: resulta da inalação de esporos. Esses casos ocorreram em espaços fechados de fábricas de processamento de couros e lã contaminados. O maior surto de anthrax pulmonar ocorreu a partir da liberação acidental, em 1979, em uma instalação militar da cidade de Sverdlovsk, antiga União Soviética, por falha no sistema de ventilação. Atualmente, muito se discute sobre a possibilidade da liberação por meio da dispersão aérea de esporos como resultado de um atentado terrorista. Os endosporos podem permanecer inativos por semanas, situando-se o período de incubação entre dois e 43 dias. Fatores ligados ao hospedeiro, dose infectante e quimioprofilaxia podem afetar a duração do período de incubação. A evolução da doença é lenta. Os primeiros sintomas ocorrem geralmente de dois a cinco dias após a exposição e são semelhantes aos da gripe, incluindo febre, mal estar, tosse, dispneia, dor de cabeça, anorexia, vômito, calafrios, fraqueza muscular, dor abdominal e torácica. Os sintomas podem progredir para uma fase aguda grave caracterizada por desenvolvimento súbito de febre, dispneia, diaforese, estertores úmidos, derrame pleural, taquicardia, choque e morte. Metade dos casos apresenta meningite, muitas vezes com hemorragia subaracnóidea. A meningite causada pelo anthrax é clinicamente indistinguível da meningite causada por outros agentes etiológicos. É a forma mais grave, mas também a mais rara, sendo letal em 90 a $100 \%$ dos casos se não for tratada rapidamente. Nos casos tratados, a taxa de mortalidade é de aproximadamente 75\% (HOLTY ET AL., 2006). 
Não existem relatos de transmissão de pessoa a pessoa, sendo o risco maior de contrair a doença por meio da inalação dos esporos de B. anthracis aerolizados.

\section{Suspeita de um ataque bioterrorista}

Ao contrário de um ataque terrorista com agentes químicos, que normalmente levam a síndromes de doenças violentas em minutos no local da exposição, o surgimento de sintomas das doenças resultantes dos agentes biológicos, incluindo $B$. anthracis, tem períodos de incubação de dias (BOSSI ET AL., 2004).

Um ataque com anthrax deve ser considerado quando há a existência simultânea de muitos pacientes com sintomas de doença pulmonar grave, corrimento nasal, presença de bacilos gram positivos em esfregaços de sangue, bem como mediastino alargado em pacientes previamente saudáveis. O B. anthracis nesse tipo de dispersão pode demonstrar resistência antimicrobiana ou maior capacidade de dispersão. Destaca-se a importância do estudo da aerosolização primária (resultante da liberação inicial) e da aerosolização secundária (resultante da suspensão de partículas depositadas no solo a partir da aerosolização primária). É difícil medir a magnitude do risco para a ocorrência do anthrax por inalação de aerosolização secundária de esporos (CDC, 2010).

Para a identificação dos casos prováveis de liberação intencional, utiliza-se a definição de caso em: possível, provável, confirmado ou deliberado. O caso possível não se aplica ao anthrax. O caso provável é aquele em que há sinais clínicos sem isolamento do $B$. anthracis ou outra prova de confirmação diagnóstica, mas com algum teste laboratorial positivo e clínica compatível com antecedente epidemiológico de exposição ambiental confirmada, sem necessidade de exames laboratoriais. O caso confirmado é aquele onde há sintomas clínicos compatíveis e com confirmação diagnóstica laboratorial (CDC, 2001).
O diagnóstico laboratorial mais utilizado é a identificação do Bacillus anthracis no sangue (hemocultura), líquido pleural, líquor ou tecidos das lesões através de esfregaços, histologia em tecidos, exames imuno-histoquímicos, Elisa e imunofluorescência. O PCR em tempo real ainda não é amplamente difundido (SWEENEY ET AL,, 2011).

Os casos deliberados estão relacionados com mais de um caso confirmado de anthrax inalado ou mais de um caso de anthrax cutâneo sem antecedente epidemiológico natural ou, ainda, com mais de dois casos suspeitos de anthrax ligados entre si pelo período temporal ou espacialmente, principalmente se os pacientes se encontravam na mesma direção do vento (CDC, 2015).

Existem alguns parâmetros para diferenciar os surtos naturais de doenças infecciosas daquelas suspeitas de serem resultantes de um ataque bioterrorista. Esses parâmetros incluem desde os padrões temporais de início da doença, número de casos, período de incubação, sintomas, resistência antimicrobiana, morbidade, mortalidade, localização e distribuição geográfica do surto, distribuição sazonal, potencial zoonótico, infectividade residual, persistência no meio ambiente e patogenicidade até a identificação de atividades terroristas consistentes (CDC, 2015). A evidência mais importante de um ataque bioterrorista é o aparecimento de grupos de doentes de forma simultânea (em intervalos de horas ou poucos dias) com quadro clínico similar, sintomas graves (especialmente entre jovens com bom estado de saúde), resistência atípica a antibióticos, fracasso ao tratamento habitual, evolução da doença de forma atípica ou mais grave, distribuição sazonal ou geográfica anômala da doença, casos agrupados simultâneos em áreas não contíguas, casos em um mesmo ambiente (sistemas de ventilação comuns) e reivindicação por grupo terrorista (BUITRAGO ET AL., 2007).

\section{Medidas de biossegurança}


$\mathrm{O}$ reconhecimento daquilo que constitui um risco depende do contexto em que se insere e envolve diferentes conhecimentos e processos. Cada risco tem suas características, apresentando maior ou menor grau de intensidade ou gravidade a partir de conjunturas mais ou menos favoráveis à sua ocorrência. É a análise da dimensão e da potencialidade do risco que irá determinar a estratégia da ação preventiva. A avaliação de risco é a ferramenta que possibilita essa análise e, a partir dela, a definição dos procedimentos de biossegurança que irão orientar as ações de promoção e proteção da saúde pública e do meio ambiente, uma vez que pode haver esporos no solo, alimentos e água.

Deve-se considerar a necessidade de elementos de proteção e de contenção, ligados fundamentalmente a três aspectos. $O$ primeiro aspecto está relacionado ao projeto arquitetônico e de engenharia onde os pacientes serão atendidos e as amostras serão processadas. O segundo se refere aos equipamentos de proteção, que podem ser individuais (EPI) ou coletivos (EPC), e o terceiro, relativo aos procedimentos e técnicas, onde devem ser adotadas condutas rigorosas de segurança.

Como não existem dados que indiquem a ocorrência de transmissão pessoa a pessoa, mesmo no caso de pacientes com anthrax pulmonar, os doentes necessitam ser internados em quarto de hospital padrão. Recomenda-se que sejam seguidas as medidas de precaução padrão para o manuseio de materiais biológicos, como sangue e fluidos corporais (DUTTA; SUJATHA; SAHOO, 2011; SWARTZ, 2001). Procedimentos de higiene, como a lavagem das mãos, cuidados na manipulação de materiais perfurocortantes e utilização de equipamentos de proteção são capazes de reduzir o risco ocupacional.

É importante destacar que a proteção respiratória é definida com base no risco de transmissão do patógeno. $\mathrm{O}$ aparelho de respiração autônomo Self Contained Breathing Apparatus (SCBA) deve ser utilizado pelos profissionais de primeira resposta para entrar nas áreas denominadas 'áreas vermelhas', onde haja dispersão de patógenos decorrentes de um ataque de bioterrorismo. Esses equipamentos são suficientes para fornecer a proteção respiratória adequada contra a dispersão de anthrax e representam o nível mais elevado de proteção. Porém, ressalta-se que os profissionais devem estar familiarizados com os requisitos físicos e as limitações impostas pelo próprio equipamento de segurança. A vestimenta protetora precisa ser impermeável e resistente aos produtos químicos, embora provoque a diminuição do arrefecimento corporal e contribua para a desidratação e stress por calor. As peças faciais de proteção podem gerar claustrofobia e os respiradores, por provocar resistência no fluxo de ar, possibilitam o agravamento de doenças respiratórias e do coração. Os SCBA, em conjunto com vestimentas de proteção do nível A, são os EPI recomendados para o atendimento em áreas onde não se conhece o tipo de patógeno de transmissão aérea envolvido no evento, o método de disseminação, a duração da dispersão e a concentração do patógeno no ar no momento do atendimento.

O diagnóstico da amostra deve ser feito em laboratórios de Nível de Biossegurança 3 (NB3), que são locais adequados aos trabalhos com agentes biológicos classificados como sendo da classe de risco 3, ou seja, aqueles que possuem risco potencial de transmissão pela via respiratória e que podem causar infecções sérias e possivelmente fatais. Nesse NB as barreiras relacionadas aos procedimentos e aos equipamentos de segurança são mais rígidas, a fim de proteger os trabalhadores, a comunidade e o ambiente contra a exposição aos aerossóis infecciosos. A manipulação das amostras deve ser feita em cabines de segurança biológica da Classe II e os aspectos relacionados á infraestrutura laboratorial incluem o acesso controlado e sistemas de ventilação que minimizam a exposição aos aerossóis infecciosos, como, por exemplo, o fluxo unidirecional com diferencial de pressão e, o ar de exaustão filtrado através de filtro High Efficiency Particulate Air (HEPA) antes de ser lançado ao meio 
ambiente. O Bacillus anthracis é classificado nesse grupo de patógenos.

Nesse caso, recomenda-se o uso de macacão confeccionado em não-tecido, com tripla camada (SMS) ou polietileno, modelo de alto nível de proteção, luvas, máscaras descartáveis com filtração (N95 ou PFF2) ou capuz acoplado a um conjunto purificador de ar motorizado, sapatos fechados e revestimentos protetores de pé. Quando a máscara for utilizada, os óculos de segurança ou protetores faciais completos deverão ser empregados para proteção das mucosas e olhos contra impactos de partículas volantes, respingos de produtos químicos e espirros de sangue e fluidos corpóreos.

As medidas de precaução de contato são requeridas quando os pacientes apresentarem rompimento das vesículas cutâneas. Recomenda-se que as lesões cutâneas causadas pelo anthrax sejam cobertas durante as primeiras 24 a 48 horas após o início do tratamento. Os curativos contendo a drenagem das lesões, assim como quaisquer resíduos gerados no atendimento do paciente são considerados resíduos perigosos, necessitando ser autoclavados ou incinerados (GREENBERG ET AL., 2010).

A desinfecção dos materiais termossensíveis e das superfícies dos veículos de transporte dos corpos pode ser feita empregando-se formaldeído a 10\% (aproximadamente $3 \%$ de formalina), glutaraldeído a 4\% (pH 8.0-8.5), peróxido de hidrogênio a $3 \%$, ácido peracético a $1 \%$ ou hipoclorito de sódio a $5 \%$. O operador deve usar roupas de proteção, luvas e protetor facial. Os materiais contaminados que resistam a altas temperaturas, assim como os resíduos, devem ser autoclavados à temperatura de $122^{\circ} \mathrm{C}$ durante 30 minutos ou incinerados (GREENBERG ET AL., 2010; WHO, 2008).

As áreas laboratoriais assim como os quartos e as áreas de isolamento de pacientes devem ser descontaminados utilizando-se solução esporicida durante 24 horas e, após este procedimento, os ambientes necessitam ser bem ventilados.

Nos casos fatais, as necropsias devem ser desencorajadas. A cremação é preferível ao sepultamento. O corpo deve ser colocado num saco impermeável para o transporte e não pode ser retirado desse envoltório. Ressalta-se que os sacos próprios (morgues) para cadáveres podem dificultar o resfriamento, assim como aumentam a velocidade de decomposição em regiões quentes.

No caso de sepultamento, o corpo ensacado deve ser colocado num caixão hermeticamente fechado e enterrado sem reabertura. $\mathrm{O}$ embalsamamento se associa a riscos especiais ao embalsamador e, portanto, deve ser evitado.

O melhor método de eliminação das carcaças de animais infectados com Bacillus anthracis é a incineração, porque esses bacilos necessitam de $\mathrm{O}_{2}$ para esporular. $\mathrm{O}$ exame post-mortem de animais não deve ser permitido, já que as formas vegetativas contidas no corpo morrem dentro de poucos dias com o processo de putrefação, mas a abertura da carcaça promove a esporulação. Como pode haver a eliminação de exsudato sero-sanguíneo pelo nariz, boca e ânus, alguns bacilos podem ser expelidos e esporular. Não há como prever o período de tempo para que não haja mais agentes viáveis dentro da carcaça, uma vez que tal condição dependerá muito das condições climáticas locais, particularmente da temperatura ambiental. Dessa forma, o enterro das carcaças contaminadas não constitui um procedimento seguro, uma vez que os esporos poderão ser encontrados no solo muitos anos depois, existindo, ainda, a possibilidade de a superfície do terreno ser removida por atividades agrícolas, drenagem ou escavação, levando a uma possível contaminação.

A administração de vacinas só é recomendada para os profissionais em ocupações de risco, sendo sua disponibilidade muito restrita. A vacinação está indicada para as forças armadas como parte de uma 
preparação para o bioterrorismo. A vacina atualmente utilizada é a vacina americana chamada Anthrax Vaccine Adsorbed (AVA) ou $M D P H-A V A$ e seus suprimentos são limitados. É utilizada em doses de $0,5 \mathrm{ml}$, subcutânea, no esquema de zero, duas, e quatro semanas e aos 6,12 e 18 meses, seguidos por reforços anuais (CDC, 2010).

Um período longo de profilaxia antibiótica é recomendado por causa do tempo de latência prolongado, que ocorre antes da germinação dos esporos adquiridos por meio da exposição inalatória do B. anthracis, num cenário de liberação deliberada. Pessoas que apresentem febre ou sinais de doença sistêmica devem ser tratadas preventivamente até que a suspeita de infecção por anthrax seja descartada. Por muitas décadas, a penicilina tem sido a droga de escolha para infecções por anthrax. Já existem relatos de resistência à penicilina em infecções naturais (LALITHA; THOMAS, 1997), casos em que as drogas são usadas são: doxiciclina e ciprofloXacina (SWARTZ, 2001).

\section{Conclusão}

Atualmente, são cada vez mais frequentes os relatos a respeito do interesse no acesso aos agentes biológicos como possíveis armas. Esse interesse não é monopólio de qualquer país, uma vez que são armas úteis por sua versatilidade em infligir mortes ou tentar atos de impacto social, com desequilíbrio psicológico e emocional de uma população, disseminação do medo, pânico, ansiedade e insegurança, provocando a perda de confiança nas autoridades governamentais e prejuízos econômicos.

O Brasil, historicamente, não é alvo para um ataque terrorista, porém existem condicionantes circunstanciais que podem fazê-lo um alvo compensatório. O Brasil, devido ao fato de ser um país protagonista em um cenário geopolítico internacional, que sedia grandes eventos esportivos internacionais com reunião de pessoas de várias nacionalidades e religiões, estará mais suscetível a um atentado desse tipo. Para tanto, necessita considerar o bioterrorismo como uma ameaça real. Nesse caso, a melhor forma de combatê-lo é por meio da socialização de informações, disseminação do conhecimento e capacitação de todos os profissionais responsáveis por atuar em situações de primeira resposta nesse tipo de evento, de forma a reconhecer com facilidade um evento de bioterrorismo e identificar a doença por meio de diagnóstico clínico preciso, permitindo o tratamento das vítimas de forma eficaz.

Estudos sobre o uso do B. anthracis como arma biológica indicam maior possibilidade de dispersão intencional por aerossóis, provocando a doença na sua forma pulmonar. O surgimento dos sintomas não será imediato, devido ao período de incubação da doença. Como os sintomas iniciais são inespecíficos e se assemelham à influenza, no caso de um surto, muitos pacientes podem buscar atendimento médico em um estágio avançado da doença, com problemas respiratórios graves, onde há maior dificuldade no tratamento. É a forma mais rara da doença, possuindo uma taxa de letalidade que varia de 90 a $100 \%$, caso não seja tratada rapidamente. A gestão do ataque de 2001 demonstrou falta de preparação do pessoal envolvido, motivando múltiplos erros ao lidar com situações envolvendo o bioterrorismo. Assim, as equipes médicas brasileiras devem ter a preparação técnico-científica e emocional para a identificação precoce dos sintomas e susceptibilidade da doença para que não cometam os mesmos erros.

É importante o fortalecimento dos esforços das equipes de urgência e emergência para a detecção precoce e controle do ataque. Os treinamentos devem ser parte do processo de educação continuada. Os planos de ação necessitam incluir a exigência de notificar quaisquer lesões ou 
doenças que possuam características de surto deliberado.

Uma boa preparação para um possível ataque bioterrorista deve se concentrar, além do suporte, num bom sistema de comunicação, rede de vigilância epidemiológica eficaz, treinamento adequado das equipes de cuidados primários e recursos materiais básicos de emergência, regionalização

\section{Referências}

ARORA, R. et al. Medical radiation countermeasures for nuclear and radiological emergencies: Current status and future perspectives. J Pharm Bioallied Sci., Mumbai, v. 2, n. 3, p. 202-212, 2010.

BEATTY, M. E. et al. Gastrointestinal Anthrax: Review of the Literature. Arch Intern Med., Chicago, v. 163, n. 20, p. 2527-2531, 2003.

BOSSI, P. et al. Bichat guidelines for the clinical management of anthrax and bioterrorism-related anthrax. Euro Surveill., Stockholm, v. 9, n. 12, p. 3-4, 2004.

BUITRAGO, M. J. S. et al. Biodefense: a new challenge for microbiology and public health. Enferm Infecc Microbiol Clin., Madrid, v. 25, n. 3, p. 190-198, 2007.

CELLO, J.; PAUL, A. N.; WIMMER, E. Chemical synthesis of poliovirus cDNA: Generation of infective virus in the absence of a natural template. Science, New York, v. 297, n. 5583, p. 1016-1018, 2002.

\section{CENTERS FOR DISEASE CONTROL AND} PREVENTION (CDC). Use of Anthrax Vaccine in the United States: recommendations of the Advisory Committee on Immunization Practices (ACIP) 2009. Morb Mortal Wkly Rep., Atlanta, v. 59, n. RR-6, p. 1-30, 2010.

. Bioterrorism. Disponível em: $<$ http://www. bt.cdc.gov/bioterrorism/overview.asp >. Acesso em: 2 set. 2015.

. Update: Investigation of anthrax associated with intentional exposure and interim public health guidelines, October 2001. Morb Mortal Wkly Rep., Atlanta, v. 50, n. 41, p. 889-893, 2001. dos recursos e infraestruturas, apoio da rede de laboratórios de saúde pública e na criação de unidades assistenciais de saúde de referência.

A rentabilidade desse esforço será dupla, já que tais recursos são os mesmos necessários para a assistência, controle e monitoramento das doenças infecciosas emergentes e reemergentes.
CLIFFORD, H. L.; FAUCI, A. S. Microbial Bioterrorism. In: LONGO, D. et al. (Org.). Harrison's Principles of Internal Medicine de Medicina Interna, Singapore: McGraw-Hill, 2011, p. 1768-1778.

DOGANAY, M.; METAN, G.; ALP, E. A review of cutaneous anthrax and its outcome. $J$ Infect Public Health, Oxford, v. 3, n. 3, p. 98-105, 2010.

DUTTA, T. K.; SUJATHA, S.; SAHOO, R. K. Anthrax: Update on Diagnosis and Management. J Assoc Physicians India, Bombay, v. 59, p. 573-578, 2011.

GREENBERG, D. L. et al. Identifying experimental surrogates for Bacillus anthracis spores: a review. Investig Genet., London, v. 1, n. 4, p. 1-4, 2010.

HOLTY, J. E. et al. Systematic review: a century of inhalational anthrax cases from 1900 to 2005. Ann Intern Med, Philadelphia, v. 144, n. 4, p. 270-280, 2006.

KLEMPNER, M. S. et al. Case records of the Massachusetts General Hospital. Case 25 -2010: a 24-year-old woman with abdominal pain and shock. $N$ Engl J Med, Boston, v. 363, n. 8, p. 766-77, 2010.

LALITHA, M. K.; THOMAS, M. K. Penicillin resistance in Bacillus anthracis. Lancet, London, v. 349, n. 9064, p. 1522, 1997.

LIU, S.; MOAYERI, M.; LEPPLA, S. H. Anthrax lethal and edema toxins in anthrax pathogenesis. Trends in Microbiology, Cambridge, v. 22, n. 6, p. 317-325, 2014.

MARTIN, G. J.; FRIEDLANDER, A. M. Bacillus anthracis (Anthrax). In: MANDELL, G. L.; BENENETT, J. E.; DOLIN, R. (Org.). Mandell, Douglas and Benett's 
Principles and Practice of Infectious Diseases. 7th ed. Philadelphia: Churchill Livingstone, 2010, p. 2715-2726.

MORSE, S. S. Biological and chemical terrorism.

Technology in Society, New York, v. 25, p. 557-563, 2003.

RADOSAVLJEVIĆ, V.; JAKOVLJEVIĆ, B.

Bioterrorism: types of epidemics, new epidemiological paradigm and levels of prevention. Public Health, New York, v. 121, n. 7, p. 549-557, 2007.

SIRISANTHANA, T.; BROWN, A. E. Anthrax of the gastrointestinal tract. Emerg Infect Dis, Atlanta, v. 8, n. 7, p. 649-651, 2002.

SMITH, H. O. et al. Generating a synthetic genome by whole genome assembly: phiX174 bacteriophage from synthetic oligonucleotides. Proc Natl Acad Sci USA, Washington, v. 100, n. 26, p. 15440-15445, 2003.

SUK, E. J. et al. Dual-Use Research and Technological Diffusion: Reconsidering the Bioterrorism Threat Spectrum. PLoS Pathogens, Florida, v. 7, n. 1, 2011.

SWARTZ, M. N. Recognition and Management of Anthrax - an update. N Engl J Med, Boston, v. 345, n. 22, p. 1621-1626, 2001.
SWEENEY, D. A. et al. Anthrax Infection. Am J Respir Crit Care Med. Am J Respir Crit Care Med., New York, v. 184, n. 12, p. 1333-1341, 2011.

WALDMAN, E. A.; ROSA, T. E. C. Vigilância em Saúde Pública. São Paulo: Faculdade de Saúde Pública da Universidade de São Paulo, 1998. (Série Saúde \& Cidadania, v. 7).

WORLD HEALTH ORGANIZATION (WHO). Anthrax in humans and animals. Geneva: WHO, 2008.

Recebido para publicação em fevereiro de 2015

Versão final em setembro de 2015

Conflito de interesses: inexistente

Suporte financeiro: Conselho Nacional de Desenvolvimento Científico e Tecnológico (CNPq), processo N. 202387/2011-9 (Pós-doutorado) 